\title{
Prediction of Energy Consumption and Structure in Hebei Province Based on GM $(1,1)$ Model
}

\author{
Cong Zhao, Lin Jiao \\ Department of Finance, Hebei Finance University, Baoding, China \\ School of Continuing Education, Hebei Finance University, Baoding, 071000, China
}

Keywords: Energy consumption; Energy structure; GM(1,1); Prediction

\begin{abstract}
With the rapid development of economy, energy demand is increasing in Hebei. Therefore, prediction of energy consumption and structure in Hebei province has importance of actual meaning significance. In this paper, total energy, coal, oil and natural gas consumption data are selected in Hebei province between 2001 and 2013. First, energy consumption and structure in Hebei province are analyzed. Second, GM $(1,1)$ forecast model is established. Then, according to the established forecast model, energy consumption and structure between 2014 and 2021 in Hebei province is predicted. Last, related suggestions on energy optimization are put forward. The results are expected to provide important scientific basis for energy utilization and planning in Hebei province.
\end{abstract}

\section{Introduction}

Grey prediction is a method that can predict the systems containing uncertainties. To find the laws of system changes, original data is generating processed by identifying development trend of dissimilarity degree between system factors. Thus, data sequence with high regularity is generated. And then the corresponding differential equation model is established to predict future development trend of things. GM $(1,1)$ prediction model with a variable and first-order differential is an important model of grey prediction. It is commonly used in energy and environment prediction because this model requires less modeling information, operates easily, forecasts precisely and is easy to test.

In this paper, total energy, coal, oil and natural gas consumption data in Hebei province between 2001 and 2013 are selected as original sequence. GM $(1,1)$ model is constructed to predict energy consumption and structure in following 20 years in Hebei province. It hopes to provide reference and scientific basis for energy development strategy and the establishment of energy planning in Hebei.

\section{Analysis of energy consumption and structure in Hebei province}

The energy data in Hebei province between 2000 and 2012 are from China energy statistical yearbook. In this paper, all the energy consumption data have been converted into standard coal and the unit is ten thousand tons of standard coal. Table one shows the energy consumption and consumption structure in Hebei province.

As shown in table 1, the total energy consumption in Hebei province seems to be increasing annually from 2000 to 2012 and its average annual growth rate is $7.95 \%$. However, the speed of total energy consumption growth is different during the period and it has periodic growth characteristic. From the table, we can see that the growth speed is rapid from 2001 to 2007.

Energy consumption structure in Hebei province is basically stable in recent years because of restriction on resources endowment and consumption structure of energy relying mainly on coal cannot be changed. Coal accounts for about 90 percent in energy consumption before 2011, but oil, gas and electricity such clean energy consumption occupies 10 percent of the total energy consumption. This shows that there is no variety in energy consumption structure in Hebei province and energy consumption has many defects. It depends heavily on coal which is non-renewable 
energy, so the renewable clean energy strengthened the large market demand, and the development of solar energy utilization technology has a broad prospect.

Table.1 Energy consumption and consumption structure in Hebei province

\begin{tabular}{|c|c|c|c|c|c|c|c|c|c|}
\hline \multirow{2}{*}{ Year } & \multirow{2}{*}{$\begin{array}{l}\text { Total energy } \\
\text { consumption }\end{array}$} & \multicolumn{2}{|c|}{ Coal } & \multicolumn{2}{|c|}{ Oil } & \multicolumn{2}{|c|}{ Natural gas } & \multicolumn{2}{|c|}{ Electric power } \\
\hline & & Total & Proportion & Total & Proportion & Total & Proportion & Total & Proportion \\
\hline 2001 & 11195.71 & 10181.38 & 90.94 & 914.69 & 8.17 & 94.04 & 0.84 & 5.60 & 0.05 \\
\hline 2002 & 12114.29 & 11125.76 & 91.84 & 898.88 & 7.42 & 84.80 & 0.70 & 4.85 & 0.04 \\
\hline 2003 & 13404.53 & 12214.21 & 91.12 & 1092.47 & 8.15 & 93.83 & 0.70 & 4.02 & 0.03 \\
\hline 2004 & 15297.89 & 14193.38 & 92.78 & 992.83 & 6.49 & 100.97 & 0.66 & 10.71 & 0.07 \\
\hline 2005 & 17347.79 & 15810.78 & 91.14 & 1389.56 & 8.01 & 130.11 & 0.75 & 17.35 & 0.10 \\
\hline 2006 & 19835.99 & 18213.41 & 91.82 & 1477.78 & 7.45 & 121.00 & 0.61 & 23.80 & 0.12 \\
\hline 2007 & 21794.09 & 19961.21 & 91.59 & 1665.07 & 7.64 & 146.02 & 0.67 & 21.79 & 0.10 \\
\hline 2008 & 23585.13 & 21783.23 & 92.36 & 1620.30 & 6.87 & 160.38 & 0.68 & 21.23 & 0.09 \\
\hline 2009 & 24321.87 & 22451.52 & 92.31 & 1622.27 & 6.67 & 228.63 & 0.94 & 19.46 & 0.08 \\
\hline 2010 & 25418.79 & 23514.92 & 92.51 & 1578.51 & 6.21 & 307.57 & 1.21 & 17.79 & 0.07 \\
\hline 2011 & 27531.11 & 24901.89 & 90.45 & 2029.04 & 7.37 & 396.45 & 1.44 & 203.73 & 0.74 \\
\hline 2012 & 29498.29 & 26433.42 & 89.61 & 2280.22 & 7.73 & 466.07 & 1.58 & 318.58 & 1.08 \\
\hline 2013 & 30250.21 & 26862.19 & 88.8 & 2329.27 & 7.7 & 586.85 & 1.94 & 471.90 & 1.56 \\
\hline
\end{tabular}

\section{Energy consumption trend prediction in Hebei province}

\section{Total energy consumption prediction}

The original sequence is total energy consumption data in Hebei province from 2000 to 2000 . GM $(1,1)$ prediction model is set up to predict the total energy consumption in Hebei province between 2013 and 2020.

According to calculation, prediction model can be get.

$$
X^{(0)}(\mathrm{k}+1)=175906.25 *\left(1-\mathrm{e}^{-0.0759}\right) * \mathrm{e}^{0.0759 \mathrm{k}}
$$

Number 0 to 12 represents year 2001 to 2013 respectively. $K$ is equal to number 13 to 20 in the model, then projection value from 2014 to 2021 can be get It is shown in table 1 .

Table.2 Primary energy consumption prediction data in Hebei province

\begin{tabular}{|c|c|c|c|c|c|c|c|c|}
\hline Year & 2014 & 2015 & 2016 & 2017 & 2018 & 2019 & 2020 & 2021 \\
\hline $\begin{array}{c}\text { Total energy } \\
\text { consumption }\end{array}$ & 34493.18 & 37213.65 & 40148.63 & 43315.14 & 46731.44 & 50417.18 & 54393.59 & 58683.67 \\
\hline
\end{tabular}

As shown in table 2, the total energy consumption in Hebei province is still set to grow in the coming years. It has 344.9318 million tons of standard coal in 2013 and 586.8367 million tons of standard coal in 2020. It increases 241.9049 million tons of standard coal and the annual growth rate is $6.87 \%$ in the eight years continually. But, the annual growth rate is $7.95 \%$ from 2001 to 2013 . Thus it can be seen that growth rate will slow because of the improvement of energy efficiency and utilization of renewable energy.

Small error probability $(\mathrm{P})$ of the prediction model is 1 which is greater than 0.95 and posteriori error ratio (c) of the prediction model is 0.188 which is lower than 0.35 . From table 3 and table 4 , we can see model prediction accuracy level is levell and the model has a high forecast precision.

Table.3 Small error probability $(\mathrm{P})$ and posteriori error ratio(c)

\begin{tabular}{|c|c|c|}
\hline Prediction accuracy level & $\mathrm{P}$ & $\mathrm{C}$ \\
\hline good (Level 1) & $>0.95$ & $<0.35$ \\
\hline qualified (Level 2) & $0.95 \geq \mathrm{P}>0.8$ & $0.35 \leq \mathrm{C}<0.5$ \\
\hline general (Level 3) & $0.8>\mathrm{P} \geqslant 0.7$ & $0.5 \leq \mathrm{C}<0.65$ \\
\hline unqualified (Level 4) & $<0.7$ & $\geq 0.65$ \\
\hline
\end{tabular}


Table.4 Actual value, fitted value and residual in prediction model

\begin{tabular}{|c|c|c|c|}
\hline \multirow{2}{*}{ Year } & \multicolumn{2}{|c|}{ Total energy consumption } & \multirow{2}{*}{ Residual } \\
\cline { 2 - 3 } & Actual value & Fitted value & -1661.11 \\
\hline 2000 & 11195.71 & 12856.82 & -1756.55 \\
\hline 2001 & 12114.29 & 13870.84 & -1560.28 \\
\hline 2002 & 13404.53 & 14964.81 & -847.27 \\
\hline 2003 & 15297.89 & 16145.16 & -70.71 \\
\hline 2004 & 17347.79 & 17418.5 & 1043.66 \\
\hline 2005 & 19835.99 & 18792.33 & 1519.65 \\
\hline 2006 & 21794.09 & 20274.44 & 1711.66 \\
\hline 2007 & 23585.13 & 21873.47 & -645.84 \\
\hline 2008 & 24321.87 & 24967.71 & -41.07 \\
\hline 2009 & 25418.79 & 25459.86 & -228.53 \\
\hline 2010 & 27531.11 & 27759.64 & 227.73 \\
\hline 2011 & 29498.29 & 29270.59 & -613.57 \\
\hline 2012 & 30250.21 & 30863.78 & \\
\hline
\end{tabular}

\section{Energy consumption structure prediction}

The proportion of electric power in energy consumption structure is less, so this paper only predicts the change trend of coal, oil, natural gas consumption. The consumption of coal, oil, natural gas in Hebei province from 2001 to 2013, as shown in table 1, is selected as the original data. Then, prediction of energy consumption structure is carried on and the calculation result (refer to table 5 and table 6) is verified with MATLAB.

Table.5.Energy consumption structure prediction model in Hebei province

\begin{tabular}{|c|c|c|c|c|c|}
\hline & $\mathrm{a}$ & $\mathrm{b}$ & Prediction model & $\mathrm{C}$ & $\mathrm{P}$ \\
\hline coal & -0.0729 & 11688.4 & $\mathrm{X}^{(0)}(\mathrm{k}+1)=170516.08 *\left(1-\mathrm{e}^{-0.0729}\right) * \mathrm{e}^{0.0729 \mathrm{k}}$ & 0.2202 & 1 \\
\hline oil & -0.0776 & 887.53 & $\mathrm{X}^{(0)}(\mathrm{k}+1)=12351.93 *\left(1-\mathrm{e}^{-0.0776}\right) * \mathrm{e}^{0.0776 \mathrm{k}}$ & 0.2745 & 1 \\
\hline natural gas & -0.2103 & 25.2307 & $\mathrm{X}^{(0)}(\mathrm{k}+1)=214.01 *\left(1-\mathrm{e}^{-0.2103}\right) \mathrm{e}^{0.2103 \mathrm{k}}$ & 0.1658 & 1 \\
\hline
\end{tabular}

Table.6 Energy consumption structure prediction data in Hebei province

\begin{tabular}{|c|c|c|c|c|c|c|c|}
\hline Year & $\begin{array}{l}\text { Total energy } \\
\text { consumption }\end{array}$ & Coal consumption & Proportion & Oil consumption & Proportion & $\begin{array}{l}\text { Natural gas } \\
\text { consumption }\end{array}$ & Proportion \\
\hline 2013 & 34493.18 & 30944.04 & $89.71 \%$ & 2528.23 & $7.33 \%$ & 624.9 & $1.81 \%$ \\
\hline 2014 & 37213.65 & 33285.56 & $89.44 \%$ & 2732.21 & $7.34 \%$ & 771.26 & $2.07 \%$ \\
\hline 2015 & 40148.63 & 35804.13 & $89.18 \%$ & 2952.65 & $7.35 \%$ & 951.73 & $2.37 \%$ \\
\hline 2016 & 43315.14 & 38513.47 & $88.91 \%$ & 3190.78 & $7.37 \%$ & 1174.46 & $2.71 \%$ \\
\hline 2017 & 46731.44 & 41427.61 & $88.65 \%$ & 3448.13 & $7.38 \%$ & 1449.33 & $3.10 \%$ \\
\hline 2018 & 50417.18 & 44562.35 & $88.39 \%$ & 3726.27 & $7.39 \%$ & 1788.64 & $3.55 \%$ \\
\hline 2019 & 54393.59 & 47934.32 & $88.12 \%$ & 4026.81 & $7.40 \%$ & 2207.29 & $4.06 \%$ \\
\hline 2020 & 58683.67 & 51561.33 & $87.86 \%$ & 4351.65 & $7.42 \%$ & 2723.85 & $4.64 \%$ \\
\hline
\end{tabular}

Table 3 shows that the established $\operatorname{GM}(1,1)$ model has higher prediction accuracy, and it can be used to forecast coal, oil, natural gas consumption in Hebei province in the next few years. The prediction results are shown in Table 4 . But the proportion of oil and gas consumption rise steadily in the future according to forecast results, especially, natural gas rise faster, which shows that the energy consumption structure will be improved to some extent. 


\section{The related suggestions on energy optimization}

According to the above conclusions and the actual situation in Hebei province, this paper puts forward the following suggestions on energy optimization.

\section{Improve energy utilization efficiency}

At present, the resident population of Hebei province is 72.41 million and the amount of automobiles is up to about 7 million. Therefore, we should deeply excavate the potential of energy utilization efficiency, improve energy technology level. Improving the energy technology level also can reduce the emission of carbon dioxide, enhance enterprise strength and product quality and implement the development of intensive low carbon economy.

\section{Optimize the energy structure}

The energy structure is limited by resource endowment, so it is difficult to change in short time, but it has big development space in energy optimization. Adjusting the energy structure is to reduce the proportion of coal, oil and other high carbon emission factors, and vigorously develop the renewable energy of low carbon, economy and clean. For example, optimize network structure, strengthen power grid construction of Hebei province, develop the photovoltaic industry and make extensive use of wind energy, solar energy and other clean energies.

\section{Summary}

With the rapid development of economy and a huge increase in population in Hebei province, non-renewable energy will not be able to meet the increasing demand of energy. Predicting the total energy consumption and energy consumption structure by using $\operatorname{GM}(1,1)$ grey prediction model in Hebei province has practical significance. Prediction results show that the total energy consumption is rising and energy consumption structure is improving but still not optimistic. Therefore, how to improve energy efficiency and develop clean and renewable energy will become a major energy problem in Hebei province.

\section{References}

[1] Xincai Gao, Yanpeng Wu. Construction of China's energy consumption system forecasting model [J]. Statistics and Decision, 2009,(5):28-29.

[2] Sijin Feng, Yuanyue Deng, Yundong Ma, Ziling Song. Grey Modeling Method for Energy Consumption Forecast of China [J]. Mathematics in Practice and Theory, 2012,41(3):78-84.

[3] Juqin Wang, Baolin Li. Energy consumption demand forecasting in Hebei province under the background of new energy based on GM $(1,1)$ Grey prediction model [J]. Reform \& Openning, 2013,(11):61-63.

[4] Minghui Zheng, Qing Wang. Energy consumption demand prediction in Hebei province based on grey system theory [J]. China Economic \& Trade Herald, 2011,(19):47-48.

[5] Huiqiang Wang, Dan Hu. The construction and application of energy demand combined forecasting model [J]. Statistics and Decision, 2008, (2) :64-66.

[6] Huixin Zhang, Jia Bai. Coal consumption forecast based on the grey system model[J]. Statistics and Decision, 2011, (23):38-40.

[7]Hoeting JA, Madigan D, Raftery AE, Volinsky CT. Bayesian model averaging: a tutorial. Statistical Science 1999;14(4):382e 417.

[8] Raftery AE, Gneiting T, Balabdaoui F, Polakowski M. Using Bayesian model averaging to calibrate forecast ensembles. Monthly Weather Review 2005;133(5):1155 e 74. 